\title{
DISRESPECT AND ABUSE DURING CHILDBIRTH OF SELF-REPORTED AND OBSERVED PREVALENCE AT A UNIVERSITY HOSPITAL IN EASTERN ETHIOPIA: FACILITY-BASED MIXED-METHOD
}

\author{
Tamirat Dasa ${ }^{1}$, Abera TURA ${ }^{2}$, Aklilu ROBA ${ }^{3}$, Biftu Geda ${ }^{3}$, Elias Wakwoya ${ }^{4}$, Kasiye \\ Gemechu $^{5}$, and Tadesse Gure ${ }^{5}$ \\ ${ }^{1}$ Hawassa University College of Medicine and Health Sciences \\ ${ }^{2}$ Haramaya University College of Health and Medical Sciences \\ ${ }^{3}$ Haramaya University, College of Health and Medical Sciences, P.O. Box 235, Harar, \\ Ethiopia. \\ ${ }^{4}$ Department of Midwifery College of Health Sciences, Arsi University, Asella, Ethiopia. \\ ${ }^{5}$ Affiliation not available
}

September 8, 2020

\begin{abstract}
ABSTRACT Introduction: The disrespect and abuse of women during maternity care are problems that have been hidden by something that truth about a situation or behind doors that do not open but significantly impact women's willingness to seek life-saving care in facilities. Disrespect and abuse are a factor that significantly impacts women's willingness to seek care in developing countries. Therefore, this aimed to assess the levels and determinants of disrespect and abuse during childbearing women in Eastern Ethiopia. Methods: A mixed-method cross-sectional study was conducted in Eastern Ethiopia. Data were collected from women by administered questionnaires upon discharge and were triangulated with direct observation of providerwoman interaction. P-values of less than 0.05 was considered statistically significant. Result: A total of 592 questionnaires were administered to postnatal women with a response rate was $99 \%$ and supplemented with direct observation of 82 episodes of provider-woman interaction. Prevalence of 28.0\% (95\% CI, 24.45-31.85) had faced disrespect and abuse. The common types of disrespect and abuse were neglect 101(17.06\%), followed by non-dignified care 100(16.89\%). Our observation revealed that $24(30 \%)$ of the provider-woman interactions had disrespect and abuse. Disrespect and abuse were common among rural residence $[\mathrm{AOR}=3.32,95 \% \mathrm{CI} 1.96$ - 5.64] and having spontaneous vaginal delivery [AOR, 2.03; 95\% CI, 1.34-3.00; $\mathrm{p}=0.001$ ] were associated factors with disrespect and abuse. Conclusion: Disrespect and abuse were reported by more than one in four women during childbirth. Rural residents and women who delivered vaginally reported being abused twice compared to their counterparts.
\end{abstract}

\section{Hosted file}

1. Manuscript.docx available at https://authorea.com/users/357168/articles/479850disrespect-and-abuse-during-childbirth-of-self-reported-and-observed-prevalence-at-auniversity-hospital-in-eastern-ethiopia-facility-based-mixed-method 